\title{
CANTOS-POEMAS DE RESISTÊNCIA: A CULTURA NEGRA NAS SALAS DE AULAS BRASILEIRAS
}

\author{
Prof. Dr. Edivaldo Conceição Santos (Pós-Crítica)
}

\begin{abstract}
"Buscar o sentido e os significados [ Do/no texto literário] é buscar o homem, é buscar-se enquanto "eu" e enquanto "o outro" é procurar e é fazer, ou refazer - a própria história" (CINTRÃO, 2003, p.12).
\end{abstract}

A literatura, oral ou escrita, pode, nos universos de sua abrangência, visibilizar contradições, paradoxos, individualidades, subjetividades, além de outras manifestações de saberes que emergem do ser humano. Por tudo isso, termina sendo também um instrumento didático relevante e, por vezes, libertário. No entanto, são pertinentes as críticas ao ensino dessa disciplina em sala de aula. Uma delas recai sobre as práticas abusivas e tradicionais da visibilidade historiográfica e sociológica por parte de alguns professores em sala de aula; ressalte-se, tanto em universidades quanto em escolas públicas. Espaços que deveriam, em princípios, primar por ideais libertários, mas que também praticam a reprodução dos modelos de ensinos homogêneos, autoritários e inibidores da criatividade humana, consequentemente, minimizando os sentidos mais amplos que os textos e os homens, nesse trânsito, se permitem.

Essa prática comum de ensino em sala de aula, além de alijar os saberes individuais de que os alunos são portadores, alija também os das diversidades culturais existentes entre os povos, pois solapa desses últimos as grandezas e riquezas que deles emanam e vivenciam cotidianamente.

São inúmeros os exemplos de perseguição e violência que a história educacional registra para com aqueles que estiveram submetidos a atos dessa natureza. As histórias de vida de alguns professores e alunos que não aceitaram e não aceitam formas violentas de negação de suas identidades, sobretudo quando estruturadas nos currículos, são um fato. Diga-se de passagem, tais currículos apresentam-se como agentes vivos das formas de dominação e visíveis nos estragos que causam a uma parcela considerável da população e dos povos que não são visibilizados como devem em suas histórias e culturas. As provas mais elementares dessa situação-problema que o cotidiano das 
instituições escolares nos oferta são as demissões e outras mazelas regimentais que ocorrem no universo escolar, diferentemente, claro, de como Selma Guimarães Fonseca (2008, p.107) compreende a escola e a educação. É dela a seguinte informação: Para nós, a escola tem a responsabilidade não só de ampliar a compreensão do mundo, mas de formar indivíduos aptos a participar e intervir na realidade. Portanto, a educação é vital na busca da felicidade, do bem comum, nas relações humanas, na promoção do humanismo. Educar é um ato de liberação, socialização, formação e transformação dos homens. É um direito do cidadão para o exercício da cidadania.

Nessa relação cultura e reprodução de currículos, lidar, portanto, com a questão da cultura é perigoso. Primeiro, porque no âmbito das relações internacionais entre os povos, ela firma valores que se querem apagados pelos países dominadores; segundo, porque nesse universo, o cidadão pode ser sujeito das suas próprias histórias e não objeto delas; terceiro, porque nesse mundo globalizado, as referências libertárias para os sujeitos podem ser utilizadas como armas de combate a todas as formas de dominação que incomodam o sistema. Enfim, possibilidades amplas de interação, pois lida diretamente com sujeitos e conhecimentos.

Nesse sentido, o saber didático e político do que seja cultura, ideologia e classe é muito importante quando aplicados em sala de aula. Essa tríade de saberes e como ela se constrói nesses espaços através de práticas tradicionais ou pós-modernas de ensino, não só ajudariam os alunos a compreenderem os problemas que os constrangem, bem como ajudariam a construir relações mais solidárias de respeito ao outro. No filme, por exemplo, Entre os Muros da escola, do diretor Laurent Cantet, os conflitos étnicosculturais em uma sala de aula da periferia de Paris são visíveis em várias cenas que resultam deles.

Todo esse conflito, resultado ainda de heranças colonizadoras fundadas em modelos subalternos, começa por negar o outro e os saberes desse outro. Isso fica claro não só nas relações cotidianas entre dominados e dominadores, bem como no próprio filme em outras cenas típicas de sistemas e de professores que ignoram as diferenças sócio-culturais existentes no seio da sociedade local.

Esse "alijar" o outro do seu modo de ser, esteja ele dentro ou não do seu país, muito embora seja uma prática concreta nos modelos de sociedade em que tais 
comportamentos violentos se fundam, é também uma forma de reproduzir relações de dominações culturais. Questões essas já amplamente estudadas por Bourdieu ao analisar as relações de dominações culturais nas escolas francesas e, por outros autores, em outros espaços, a exemplo de Raymond Williams, Edward Said, entre outros.

No caso da Literatura Brasileira produzida por autores negros e não-negros, a cultura de matriz africana e o seu ensino ainda são vistos em algumas escolas como um "fardo" a ser carregado por alguns professores. Tal comportamento é resultado ainda dos muitos anos de silêncios impostos na sociedade brasileira ao povo negro e suas manifestações artísticas e culturais.

Dessas violências cometidas contra esse povo, agrega-se, ainda, no âmbito da formação dos professores, as carências e saberes necessários para lidar com temas dessa natureza em sala de aula. Tema esse tão vivenciado entre os povos formadores da sociedade brasileira, mas, ao mesmo tempo, alguns deles ainda invisibilizados no processo da educação formal.

Em meio a esse cenário controverso e de tensões, tentou-se apagar, dessa cultura, as suas representações mais significativas nesses espaços, ficando evidenciados tão somente os cerceamentos e impossibilidades do homem negro contar as suas histórias, exceto aquelas que as suas memórias e desejos não permitiram ser apagadas.

Contemporaneamente, os esforços para ultrapassar os grandes períodos de silêncio impostos aos autores negros, começam a ruir. Tal prática está evidenciada pelo esforço pessoal e de algumas instituições em trazer nomes importantes de autores negros para a sala de aula das escolas brasileiras. Esse movimento, diria, ainda conflituoso, desconstrói o que houvera antes sido deliberado pela classe dominante. Nesse sentido, apoiada pelas escolas, através da utilização de livros didáticos discriminadores, racistas e equivocados, bem como pelos currículos escolares de base eurocêntrica, cristã, hétero e branco, em cujas premissas e textos assentam-se as exclusões. Claro, além das subjetividades que norteiam as compreensões humanas. Mesmo porque, os alunos são diferentes uns dos outros, idem, portanto, para as suas histórias, só que as escolas fingem que não veem isso.

É de DAYRELL a seguinte reflexão: 
Os alunos chegam à escola marcados pela diversidade, reflexo dos desenvolvimentos cognitivo, afetivo social, evidentemente desiguais, em virtude da quantidade e qualidade de suas experiências e relações sociais, prévias paralelas à escola. $\mathrm{O}$ tratamento uniforme dado pela escola só vem consagrar a desigualdade e as injustiças das origens sociais dos alunos. (p.140)

No bojo das lutas dos negros contra as invisibilidades e a favor da afirmação de sua cultura, valores, identidade, cidadania, etc., antes, portanto, da existência de Lei da 11645/08, cujo teor determina o ensino obrigatório da História e da Cultura Afrobrasileira e Africana e Indígena em sala de aula da nação brasileira, os negros já praticavam sua cultura nos terreiros de candomblés, à revelia, portanto, das instituições que os mantinham de fora do processo legal e civilizatório da nação brasileira.

É bom ressaltar que a Lei referida no parágrafo anterior é louvável, mas ela vem para a cena brasileira em decorrência das lutas constantes dos negros do Brasil para tornarem-se cidadãos com direitos e deveres de um brasileiro comum, mas que conhecem as tramas das relações de poderes. Evidentemente que essas reivindicações, $a$ posteriori, fundam-se nos exemplos dados por outros movimentos artísticos e sociais que aconteceram dentro e fora do país.

No caso brasileiro, a referência maior dessa luta é dada pelo herói negro Zumbi dos Palmares no século XVI, Revolta dos Búzios (XVIII), Rebelião dos Alfaiates na Bahia (XVIII), Rebelião Malê também na Bahia (XIX), além de tantas outras referenciadas pelo historiador João José Reis no livro "Rebeliões Escravas no Brasil; A História do Levante dos Malês em 1835 em que destaca o papel revolucionário dos escravos brasileiros em luta pela liberdade. Registre-se, ainda, o papel da Imprensa Negra Brasileira (XX), o papel exemplar de Abdias do Nascimento fundador do TEN Teatro Experimental do Negro ( $\mathrm{XX}$ ), as atuações do Movimento Negro Unificado Brasileiro (XX) além de movimentos culturais de resgate, atuação política e afirmação de expressões culturais que se queriam apagadas na sociedade brasileira. Uma luta, portanto, contrária às práticas racistas ainda presentes nesta mesma sociedade.

Além disso, os exemplos dados pelos grupos culturais como Ilê Ayê, Muzenza, Oludum, Araqueto, na Bahia, bem como outros exemplos oriundos de outros estados 
brasileiros são importantes por manterem acessa a chama das igualdades nas diversidades dos povos. Povos esses, subalternizados pelas culturas hegemônicas.

Para além desses movimentos artísticos e culturais nascidos em terras brasileiras, outros gestados fora dos limites desse país reforçam a luta dos negros para afirmação da sua cultura. Um exemplo típico vem da luta dos negros pela independência do Haiti (XIX) sob o jugo do colonizador americano; do movimento artístico denominado New Negro ou "Negro Renaissance" nos Estados Unidos, surgido no Harlem (XX) e gestado nos exemplos da luta de libertação do povo escocês, à época colonizado pela Inglaterra, (século XX), além de outros movimentos como o Black Power norteamericano, O "Negrismo" cubano; o Indigenismo no Haiti; o movimento da Negritude na Europa da década de trinta do século XX. Este último, ressalte-se, liderado por homens como Senghor, Damas, Aimé Cesaire, bem como em outras negritudes espalhadas no mundo, nos exemplos antes dados pelo pensador negro W.E.Dubois no século XX nos Estados Unidos, além de outros escritores como Langston Hughes, Claude Mackay e Richard Wright.

Toda essa movimentação de fluxo e refluxo de idéias passadas e presentes alimentará e servirá para fortalecimento de outras formas de expressões artísticas como a literatura pós-colonial, resultado das vozes de autores negros e de autores brancos que em suas humanidades fazem-se presentes no cenário literário e artístico contemporâneo, tanto dentro quanto fora da África.

Tais textos, é bom que se diga, refletem, remetem, espelham, transgridem e denunciam as violências cometidas sobre o continente africano muito antes do século XVI e, até hoje, alimentadas pela cultura negativa do espetáculo midiático em que o capital dos ricos determina o que o povo pode e não pode ver.

Enfim, toda essa história das lutas e saberes dos negros e de brancos que já deveriam ter estado em sala de aula e que deveriam ser parte integrante do capital acumulado da formação dos professores para atuarem junto aos alunos e, em função de um ensino de qualidade, respeito ao outro, ainda não estão, apesar dos PNCs trazerem as seguintes orientações estéticas, políticas e étnicas:

Como expressão de identidade nacional, a estética da sensibilidade facilitará o reconhecimento e valorização da diversidade cultural brasileira e das formas de 
perceber e expressar a realidade própria dos gêneros, das etnias e das muitas regiões e grupos sociais do País. (BRASIL, 1999, p.76).

No bojo dessas orientações, bem como os exemplos que vêm das vozes dos negros e de autores brancos que os tematizam em seus cantos-poemas, são extremamente importantes, pois não só reivindicam uma sociedade mais justa, mais digna, mais solidária, mas também porque denunciam as condições brutais em que os negros foram obrigados a deixarem seus países de origem por mares e travessias que se confundiram com suas lágrimas, além de estar coladas com os modos de vida do sernegro.

Nesse sentido, portanto, sons e letras de canções-poemas, velhas e atuais veiculam informações que remetem relações de pertencimento da cultura local e, quiçá, universal. Tal recurso didático-libertário, em sala de aula, só redimensionaria o que, de certa forma, os negros já vivenciam em suas práticas culturais, ou seja: o espetáculo da vida. É de Ferreira (p.10. 2001) a seguinte afirmação:

Muitas vezes é mais eficaz perpetuar um pensamento transmitido verbalmente pelo canto que pela escrita no papel (...). A Música, o som ordenado, assim como é uma linguagem universal também é uma linguagem por meio da qual uma idéia é mais bem difundida ao longo dos tempos: mesmo sem escrever quaisquer sinais gráficos que representasse os sons que cantavam.

Com base nesses saberes, é que os PCNs atribuem, ainda, à escola um papel fundamental quando sobre ela se pronuncia:

A escola deve assumir a valorização da cultura de seu próprio grupo e, ao mesmo tempo, buscar ultrapassar seus limites, propiciando a crianças pertencentes aos diferentes grupos sociais o acesso ao saber, tanto no que diz respeito aos conhecimentos socialmente relevantes da cultura brasileira no âmbito nacional e regional, como no que faz parte do patrimônio universal da humanidade. Para tanto, é preciso que a escola esteja enraizada na comunidade (PCNs- Fundação social da Escola - Ensino Médio. 
Todo esse potencial da escola e textos circulando dentro desse espaço devem estar a serviço dos povos em suas desigualdades culturais, além de ter no professor o agente capaz de fazer a vida acontecer.

Ressalte-se ainda que, um ensino dessa natureza, produziria outras formas de construções culturais e relacionamentos, aqui pensados como especiais, sobretudo quando politizados com o fim de praticar outros comportamentos que se fundem nas convivências das cores, das raças, das questões de gênero e de fronteiras como possibilidade da construção de um mundo melhor. Além disso, essas canções podem ser contra as lógicas destrutivas que presidem o mundo contemporâneo, pelas críticas corrosivas que os autores engendram contra as engrenagens que estão a serviço do capital.

Ao produzirem e cantarem suas canções, os negros, simultaneamente, as revestem designos lingüísticos importantes para corroborarem para não deixar a língua de suas origens morrerem. Essa forma de legitimação, além das que são mostradas através dos ritos dos terreiros de candomblé, encontram-se em muitos compositores brasileiros, dentre eles Milton Nascimento, Caetano Veloso, Gilberto Gil e outros. Mesmo porque, a força cósmica, de que a música e a língua são portadoras em diversas manifestações culturais, está preservada através de muitas gerações pelo povo-de-santo pobre da Bahia que sempre primou pelo desvelo e cuidados conscientes ou inconscientes, mas que foram e são fundamentais para a preservação do patrimônio linguístico-culturalidentitário dos negros na Bahia e, a escola, espera-se, deve dar continuidade a esse trabalho poético.

\section{REFERÊNCIAS}

BRASIL, Ministério da Educação, Secretaria de Educação Média e Tecnológica. Parâmetros Curriculares Nacionais: Ensino Médio. Brasília: Ministério da educação, 1999.

CINTRÃO, Sylvia H. O Contágio-Social da Literatura . IN: Água Viva: Revista de Estudos Literários. $\mathrm{N}^{\circ} 2$. Brasília: Jan/Jun 2003. p.11-18.

CHAUI, Marilena. O que é Ideologia. São Paulo: Brasiliense, 2004 (Coleção Primeiros Passos;13). 
CHIAVENATO, Júlio José. O Negro no Brasil: Da Senzala à Abolição. São Paulo: Moderna,1999.

CUNHA Jr. Henrique. As Estratégias de Combate ao Racismo. Movimentos Negros na Escola, na Universidade e no Pensamento Brasileiro. In MUNANGA, Kabengelê (org.). Estratégias e Políticas de Combate a Discriminação Racial. São Paulo: Edusp, p.147156. São Paulo: Paz e Terra, 1996.

DAYRELL, Juarez Tarcisio. A Escola como Espaço Sócio-Cultural. IN Juarez Dayrell (org) Múltiplos Olhares sobre Educação e Cultura. Belo Horizonte: Editora da UFMG, 1996, p.136-161.

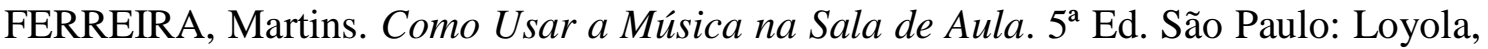
2002.

FREIRE, Paulo. A importância do Ato de Ler: em três artigos que se completam. $44^{\mathrm{a}}$ Ed. São Paulo: Cortez, 2003.

REIS, João José. Rebelião escrava no Brasil; A História do Levante dos Malês em 1935. São Paulo: Companhia das Letras.

TORRES SANTOMÉ, Jurjo. As culturas Negadas e Silenciadas no Currículo: IN: Alienígenas na sala de aula: Uma Introdução aos Estudos Culturais em Educação.

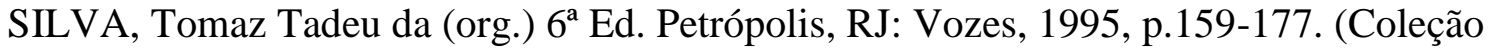
Estudos Culturais em Educação).

ZILBERMAN, Regina. A teoria da Literatura e a Leitura na Escola. IN: A leitura e o ensino da Literatura. São Paulo: Contexto, 1988. p.121 a 137.

RECEBIDO EM: 04 de maio de 2011

APROVADO EM: 02 de junho de 2011 